\title{
DERECHO Y PRÁCTICA LEGAL EN LAS COMUNAS URBANAS ITA- LIANAS DEL SIGLO XIY: EL CASO de PISA
}

por

\section{CHRIS WICKHAM}

Universidad de Birmingham. Inglaterra

RESUMEN: Pisa no fue una ciudad tipica en la Italia del siglo Xll; grande y comercialmente próspera, con instituciones urbanas precoces, destaca, sobre todo, por su adopción del Derecho Romano con un grado de compromiso mayor que cualquier otra entidad politica a lo largo del siglo. Este articulo se centra en la forma en que Pisa incorporó el Derecho Romano en sus dos Constituta, promulgadas en $1160, y$ en el complejo aparato de acciones romanas, incorporado al sistema judicial comunal desde 1159. De hecho, parece que los pisanos utilizaron casi por entero el Corpus Iuris Civilis en sus disputas, sin dificultad. Para examinar el efecto que esto tuvo en las concepciones pisanas sobre la forma en que Derecho y sociedad se interrelacionan, se discute un conjunto de casos. A partir de ellos, se hace mas claro que Pisa sólo se romanizó en algunos aspectos. Así, la creencia de los pisanos, como la de sus contemporáneos en el resto de Italia, en que la defensa violenta de la propia posesión prueba en si misma el derecho. En los litigios se nos cita a menudo esa violencia, en ocasiones incluso justificada mediante argumentaciones de estilo romanista, aunque el Derecho Romano se oponía por completo a tales actitudes. Este articulo puede ayudar a mostrar la forma en que una ciudad, en otros sentidos típica, pudo ser la primera en aplicar el Derecho Romano: adaptando éste a los presupuestos locales.

Palabras clave. Derecho. Italla. Tribunales. Sentencla. Litigaclón. Política. Violencia. Jurisprudencia

ABSTRACT: Pisa was an atypical city in 12th-century Italy; it was large and commercially prosperous, with precocious urban institutions, and, above all, it adopted Roman law with more commitment than any other polity in the century. This article looks at the way Pisa absorbed Roman law, in its two Constituta, promulgated in 1160, and in the complex array of Roman actions, which where received into the Pisan communal coun system

Hispania, LVIL/3, núm. 197 (1997) 981-1007 
from 1159 onwards. The Pisans seem in fact to have had the capacity to use almost the whole of the Corpus Iuris Civilis in their disputing with little obvious difficulty. A series of case studies are discussed, in order to see what effect this had on Pisan conceptions of the way law and society interrelate. Here, it becomes clearer that Pisa had not become Romanised in more than a few respects. In particular, Pisans evidently believed, like their contemporaries in the rest of Italy, that violent defence of one's possessions in itself proved right. Cases often cite such violence: sometimes it is even justified with Roman-style arguments, although Roman law was entirely opposed to such attitudes. This may help to show how an otherwise typical city could have absorbed Roman law in the first place: by adapting it to local presuppositions.

Key words: Law. Disputes. Italia. Courts. Judgment. Pleading. Politícs. Violence. Jurisprudence.

La Italia del siglo XII constituye, sin duda, el centro más importante de estudios jurídicos en Europa. Allí surgieron numerosas escuelas, adscritas a tres distintas tradiciones: el Derecho Lombardo y feudal, estudiados en Pavía y Milán, el Canónico, en Bolonia y Roma, y el Derecho Romano, estudiado en Bolonia junto con un grupo cada vez mayor de pequeñas escuelas en la llanura del Po. La educación jurídica, adquirida en cualquiera de ellas, se convierte hacia finales de siglo en un requisito cada vez más ventajoso para seguir una carrera administrativa en una comuna urbana italiana y, algunas veces, también más allá de los Alpes. Recordemos cómo, en 1158, Federico Barbarroja ya había llamado a los maestros boloñeses en Derecho Romano para procurarle bases legales e intelectuales con que dar cobertura a sus pretensiones de poder en Italia. Estos juristas, además de enseñar y aconsejar a los políticos, escribieron libros, en algunos casos de una extensión sin paralelo desde el Corpus Iuris Civilis de Justiniano.

Estos procesos son, desde luego, bien conocidos. No obstante, lo que a menudo no se tiene en cuenta es el hecho de que el contexto político en que tuvieron lugar fue muy diferente. Las comunas urbanas de la Italia septentrional y central no se formaron rápidamente. Durante toda la primera mitad del siglo XII su autoridad fue vacilante, sus instituciones embrionarias, y sus cargos poco estables. A mediados de siglo algunas ciudades, especialmente Milán, Génova y Pisa, parecen haber desarrollado estructuras de gobierno, incluida la administración de justicia, bastante estables, y en la década siguiente podría añadirse a aquéllas media docena más, como Bolonia o Luca; sin embargo, muchas otras comunas apenas sí han desarrollado en 1200 cierta identidad institucional. Cuando Barbarroja combate a las ciudades italianas del Norte en las décadas de 1160 y 1170 , se enfrenta a unidades casi independientes, paulatinamente más ricas y seguras de sí, y capaces de levar ejércitos con los que derrotar a señores rurales, ciudades rivales, y eventualmente, por supuesto, al mismo emperador; pero estas comunas no habían alcanzado, en la mayor parte de los casos, una gran estructuración interna. De

Hispania, LVII/3, núm. 197 (1997) 98!-1007 
hecho, el término commune, como sustantivo, sólo surge en el latín de la segunda mitad del siglo, y la consciencia de una autonomía especificamente comunal rara vez se encuentra presente en las ciudades con anterioridad ${ }^{1}$.

En términos políticos, por tanto, el contexto urbano de la Italia septentrional y central supuso, sólo de hecho, la lenta cristalización de un nuevo sistema político que durante mucho tiempo apenas fue reconocido y todavía menos teorizado. Sistema que, por su informalidad, se encontraba en el extremo opuesto de las escuelas de Derecho. Incluso la autoridad soberana del rey o del emperador, punto central tanto del Derecho Lombardo como Romano, resultaba también difícil de situar para las comunas italianas, como reconocieron los propios juristas y líderes comunales cuando se reunieron en 1158 con Barbarroja en Roncaglia. En estas circunstancias, podría fácilmente suponerse que la nueva teoría legal apenas habría tenido alguna utilidad en el desarrollo de los sistemas judiciales urbanos, y particularmente el Derecho Romano que, a diferencia de las otras dos tradiciones escolásticas, tenía poco arraigo en las prácticas consuetudinarias de la mayor parte de la Península Italiana ${ }^{2}$.

En realidad, lo cierto fue lo contrario: las ciudades fueron receptivas al Derecho sistematizado, y la del Derecho Romano se convirtió pronto en la más prestigiosa de las tres tradiciones. No obstante, se podría argumentar, esta vez con mayor convicción, que el Derecho Romano influyó lentamente en la práctica legal de las ciudades. Ciertamente, los magistrados urbanos pudieron tener una educación boloñesa, pero las ciudades poseían sus propias normas consuetudinarias, más vinculadas a, y evolucionadas a partir de, la tradición jurídica lombarda. Gracias a la formación de los notables urbanos, el Derecho Romano y sus rituales forenses penetraron esa tradición, aunque se necesitó un amplio período de tiempo. En Milán, por ejemplo, o en Luca, a pesar de poder acceder al conocimiento de la teoría legal romana, la práctica legal local fue decididamente no romana hasta bien entrado el siglo XIII e incluso más tarde ${ }^{3}$.

1 Para una visión de conjunto, PINI, A. I., Cittò, comuni e corporazioni nel medioevo italiano, Bolonia, 1986, págs. 59-81; sobre el origen incierto de la comuna, vid. KELLER, H, «Gli inizi del comune in Lombardian, en BORDONE, R. y JARNUT, J. (eds.), L'evoluzione delle città italiane nell' $\mathrm{XI}$ secolo, Bolonia, 1988, págs. 45-70; sobre la tardía aparición del término commune, vid. BANTI, $O$., "Civitas" e "commune" nelle fonti italiane dei secoli XI e XID, reeditado en RossETT,, G. (ed.), Forme di potere e struttura sociale in Italia nel Medioevo, Bolonia, 1977, págs. 217-232; para la tardia consciencia comunal, consultar WiCKHAM, Ch., Land and power, Londres, 1994, págs. 295-312.

Este artículo constituye una primera versión de uno de los capítulos de mi próximo libro sobre justicia y disputas en la Toscana del siglo XIl, Law, custom and conflict.

2 Sobre la tradición lombarda, véase RADDING, C., The origins of medieval jurisprudence, New Haven, 1988. Y sobre ta romana en el siglo XII, CORTESE, E., Il diritto nella storia medievale, II, Roma, 1995, especialmente págs. 13-195 para los juristas; y PADOA SCHIOPPA, A., «Il ruolo della cultura giuridica in alcuni atti giudiziari italiani dei secoli XI e XIL», en Nuova rivista storica, LXIV (1980), págs. 265-89, para la práctica jurídica.

3 Para Milán, vid. PADOA SCHropta, A., «Aspetti della giustizia milanese dal $x$ al $x I l$ secolo», en Atti dell 11. ${ }^{\circ}$ Congresso intemazionale di studi sull' alıo medioevo, Spoleto, 1989, págs. 459-549, especialmente págs. 541-9. Para Luca WICKHAM, Ch., Law, custom and conflict, op. cit., capítulos 2 y 3.

Hispania, LVIL/3, núm. 197 (1997) 981-1007 
Es en este contexto que Pisa se nos aparece como un interesante campo de pruebas, al ser una de las primeras ciudades que expresamente abrazó el Derecho Romano como base de su constitución urbana. No fue un caso único; Roma, Ravena, Bolonia y Génova, entre otras, siempre vivieron bajo una versión consuetudinaria del Derecho Romano, y otras ciudades, como Siena, lo adoptaron también en el curso del siglo xil. Pero pocos lugares se mostraron tan entusiastas en su adopción como Pisa. En 1155 la ciudad designó a un grupo de constitutores con la finalidad de sistematizar el Derecho de la ciudad; el 31 de Diciembre de 1160 los pisanos promulgaban, formalmente, un doble código que inmediatamente entraba en vigor: la Constitutum legis y la Constitutum usus. Se conservan varios manuscritos de dichos códigos, el más temprano de los cuales data de cerca de 1186; es evidente que fue constantemente revisado y puesto al día, y también ampliado: el texto de 1186 abarca 124 páginas en el manuscrito, pero el manuscrito de 1233, editado en el siglo XIX, se amplía significativamente a las 380 páginas de la edición impresa. La división entre los dos códigos es compleja y, en ocasiones, algo artificial. Se puede afirmar, no obstante, que la Constitutum legis está muy influida por el Derecho Lombardo y justinianeo, que a menudo cita expresamente, y la Constitutum usus se centra más en la costumbre local, aun cuando aquí también el Derecho Romano ejerció una considerable influencia. La mezcla resultante fue acaso ya más romana que lombarda, aunque (como se indica en un célebre párrafo de la Constitutum legis) retentis quibusdam de lege Longobarda; sin embargo, en subsiguientes revisiones el elemento lombardo se reduciría progresivamente, mientras el romano se incrementaba 4.

La importancia del compromiso romanista de los pisanos se hace evidente ya en esta relación de su legislación, pero se extendió más allá. Antes de la década de 1150 no se habían mostrado especialmente romanistas en sus actividades e intereses legales, aunque sí parece existir alguna enseñanza del Derecho Romano en la década de 1120 , y uno de sus más influyentes jueces y representantes ciudadanos en las décadas centrales de la centuria, Burgundio, tradujo los apartados en griego de las Digesta al latín. Manuscritos del Codex

4 El texto de 1186 se encuentra en la Beinecke Library, Universidad de Yale, MS 415; el texto de 1233 está editado por BonaINI, F., Statuti inediti della città di Pisa dal xII al xIV secolo, II, Florencia, 1854-70, págs. 645-1026. En cuanto a los estudios más importantes, vid. ClASSEN, P., Studium und Gesellschaft im Mittelalter, Stuttgart, 1983, págs. 82-98; y STORTI STORCH, C., «Il Costitutum legis pisano nella redazione del manoscritto di Yale. Prime note», en Rossetri, G. (ed.), Tradizioni normative cittadine, en prensa (agradezco a la profesora Storti Storchi el haberme permitido consultar el manuscrito del artículo). En este último trabajo, la profesora Storti Storchi sostiene que sólo la Constitutum usus puede datarse claramente en Diciembre de 1160, y propone que Ja Constitutum legis no se promulgó formalmente hasta algunos años después. Su argumentación es convincente, aunque debe tenerse en cuenta que existen algunas citas aparentemente tempranas de la Constitutum legis ante los tribunales: así en CarRatori L. y G. Garzella (eds.), Carte dell Archi. vio Arcivescovile di Pisa. Fondo luoghi vari, I, Pisa, 1988, núm. 3 (a. 1161); o en Archivio di Stato di Pisa, Fondo Diplomatico (en adelante ASP), S. Lorenzo alla Rivolta, 18 de Marzo de 1165, documento editado por GIUSTI, A., Le pergamene dell' ASP dal JI57 al IJ65, Tesi di Laurea, Universidad de Pisa, año académico (en adelante a. c.) 1967-68, relaṭor (en adelante rel.) VioLANTE, C., núm. 69.

Hispania, LVII/3, núm. 197 (1997) 981-\$007 
Justinianus, las Institutiones y las Novellae se encontraban disponibles en muchos lugares en el siglo XI, incluida Pisa, pero de las Digesta eran más raros; en cualquier caso, Pisa poseía, como muy tarde hacia 1150, lo que permanece como el mejor y más antiguo texto de dicho trabajo, la Littera Pisana (más tarde Florentina), que los mismos boloñeses pronto comenzaron a consultar ${ }^{s}$.

Sin embargo, estos distintos elementos no muestran aún un especial compromiso pisano con la práctica romana, porque sus procedimientos legales de la primera mitad de la centuria no son inusuales en la forma, y el interés por los textos justinianeos es también común a otras ciudades. Pero la década de 1150 marca un acentuado cambio en Pisa, no sólo en la legislación sino en la práctica judicial. De hecho, uno de los más acusados cortes que he observado en la tradición de registrar los procesos judiciales tiene lugar en Pisa en 11591160, aproximadamente un año despues de la promulgación de los códigos: se hace de pronto mucho más romana en todos los sentidos. Lo que puede observarse de forma más evidente en el uso por las partes de acciones romanas para dar cobertura a sus demandas. Estos actos ${ }^{6}$ se encuentran, a menudo con gran detalle, al comienzo de docenas de casos pisanos desde 1159 en adelante; además, no derivan fundamentalmente de los códigos pisanos, sino, en la mayor parte de los casos, directamente del Corpus Iuris, mostrando cómo los intereses romanizadores de los constitutores habŕan, así mismo, legitimado los préstamos directos del Derecho justinianeo ${ }^{7}$. Este entramado legal, añadido a los cambios en el contenido del Derecho que resultan de las Constituta, puso en marcha una romanización radical de la práctica que fue más allá de lo ocurrido en cualquier otra ciudad, incluidas Génova y Roma, e incluso Bolonia.

¿Por qué sucedio esto en Pisa en particular? Es díficil de explicar. Pisa, es cierto, era una ciudad poco usual en muchos aspectos. En ella se documenta la primera comuna italiana, en la década de 1080; y aunque sus instituciones comunales no surgieron con la misma celeridad, es cierto que fueron relativamente tempranas, pues entre $1130-1160$ se pusieron las bases tanto del sistema comunal judicial como del sistema fiscal local ${ }^{8}$. La ciudad del Arno,

5 Sobre todo ello, vid. CLAsSEn, P., Studium und Gesellschaft im Mittelalter, op. cit., págs. 3943. Para los bolofieses, Capriol,, S., «Visite alla Pisana», en Le Pandelte di Giustiniano. Storia $e$ fortuna di una codice illustre, Florencia, 1986, págs. 37-98, especialmente págs. 63-64.

6 Término que incluye no sólo actiones sino condictiones e interdicta, procedimientos introductorios de que se sirve el demandante, y las exceptiones, utilizadas como respuesta por el demandado.

7 La principal fuente de información sobre acciones en Pisa se encuentra en D'AMIA, A., Diritto e sentenze di Pisa, Milan, 1962, págs. 51-79 y 113-23. Vid. también CELLl, R., Studi sui sistemi normativi delle democrazie comunali, 1, Florencia, 1976, págs. 64-69. Algunas acciones citan el Derecho Pisano y también el Lombardo; pero la mayoria son de componente justinianeo en origen.

8 Resulta fundamental VolPE, G., Studi sulle istituzioni comunali a Pisa, Florencia, 1970, 2." edición. El análisis más reciente se encuentra en RonZANI, M., Chiesa e "civitas» di Pisa nella seconda metà del xu secolo, Pisa, 1997; éste cita la abundante bibliografia, sobre el periodo, producida en los últimos treinta años. Para tribunales, vid. D'AMIA, A., Diritto e sentenze di Pisa, op. cit., págs. 88-106. Para impuestos, consultar el Breve consulum de 1 162, editado por BonAinI, F., Statuti inediti della cittò di Pisa dal XIl al xIV secolo, op, cit., l, págs. 4-5, y CATUREGLI, N. (ed.), Regesto della chiesa di Pisa, Roma, 1938 (en adelante RP), núm. 492 (a. 1166).

Hispania, LVI1/3, nủm. 197 (1997) 981-1007 
como es bien conocido, constituyó también uno de los centros comerciales más activos de la Europa del momento, con un importante territorio colonial en las islas del Mediterráneo occidental (en disputa con su rival Génova) y centros comerciales en los puertos de Levante. Era una ciudad grande y activa, con unos 25.000 habitantes al menos al comienzo del siglo xirl. Rasgos que no fueron suficientes por sí mismos para hacer que Pisa adoptara el Derecho Romano en su legislación (algo que tampoco había sucedido en ciudades importantes como Milán). Pero Pisa sí desarrolló una gran confianza en sus posibilidades, como la suntuosa decoración de su complejo catedralicio aún nos recuerda; los poemas laudatorios dedicados a la ciudad, durante este período, incluso la comparan con la antigua Roma ${ }^{9}$. Esta imaginería romana debió constituir uno de los principales impulsos que empujaron a Pisa a adoptar el Derecho Romano; el deseo de ir por delante de su rival genovés, que siempre había tenido una tradición legal romanista, debió constituir el otro. En cualquier caso, los pisanos hicieron una clara elección y se aferraron a ella; si quisieron ser más romanistas que sus rivales, evidentemente lo lograron.

Más importante para nosotros resulta la cuestión acerca de la diferencia que introdujo el Derecho Romano en la práctica judicial. De hecho, esta es la cuestion fundamental a analizar en este artículo. Pisa se entregó totalmente a su compromiso romanista, hasta el punto de poder afirmarse que las élites de la ciudad del Arno consideraban el Corpus Iuris Civilis, en su conjunto y desde un plano al menos teórico, como relevante para sus asuntos. Pero la Pisa del siglo XII no poseía el vasto y complejo entramado institucional del Bajo Imperio Romano que ese Derecho implicaba. Era una ciudad comunal como otras del período, con una organización financiera poco desarrollada y una población reducida. Tenía varios tribunales, donde se juzgaban distintos tipos de asuntos, pero todos compartían la misma estructura: dos magistrados para atender el caso, un escribano para registrarlo, un delegado para ejecutar la sentencia, un missus o nuntius para actuar en su nombre, y, probablemente, algunos hombres armados para respaldar a éstos ${ }^{10}$. Otras personas pudieron estar implicadas pero su participación no ha quedado documentada. Este es el armazón de un sistema judicial basado en su modelo del Imperio Romano, aunque ya bastante extendido en la Alta y Plena Edad Media. No habia abogados presentes para representar a la gente ante el tribunal (aunque se podía

9 Sobre población, vid. Salvatori, E., La popolazione pisana nel Duecento, Pisa, 1994, págs. 116-123. Sobre la poesía y la imaginería romana, SCALIA, G., «Romanitas pisana tra XI XII secolo», en Studi medievali, XIII (1972), págs. 791-843; FISHER, C., "The Pisan clergy and an awakening of historical influence in a medieval commune», en Studies in medieval and Renaissance history, III (1966), págs. 143-219.

${ }^{10}$ Vid. D'AMia, A., Diritto e sentenze di Pisa, op. cit., págs. 155 y ss., y págs. 177-178. Se puede encontrar una buena ilustración del proceso en ASP, Carte Lupi I, págs. 846-847, 21 de Julio de 1198 (data moderna 1197); las Carte Lupi son registros modernos de documentos que se encuentran en el Archivio della Certosa, en Calci (en adelante ACC). El coste básico de un juicio civil equivalía al $5 \%$ del valor de la propiedad reclamada, como se observa en Constitutum legis, l, editado por BonaIN, F., Statuti inediti della città di Pisa dal XIl al XIV secolo, op. cit., II, pág. 648 (perdida en el manuscrito de Yale).

Hispania, LVI/3, nún. 197 (1997) 981-1007 
disponer de su consejo entre bastidores); y, sobre todo, el brazo ejecutivo era muy simple y carecía de la fuerza necesaria para imponerse en caso de ser desafiado ". Los sistemas legales que carecen de capacidad para ejercer una coerción sistemática, sólo pueden funcionar si son generalmente aceptados como legítimos por las partes y los observadores, y, como veremos, esto parece que es lo que sucedía en Pisa. Pero esto supone poner el énfasis en el ciudadano medio pisano más que, como implícitamente se ha hecho en las páginas precedentes, en los expertos legales y las élites políticas. De hecho, si queremos comprender cómo funcionaba la justicia pisana en la práctica, debemos observar el uso que los pisanos hacían de ella, sus valores, sus espectativas y estrategias como litigantes, en lo que no se mostraron tan romanistas como su ley. Este será el tema del resto del artículo. A continuación me centraré en ejemplos, en casos específicos descritos con cierto detalle. Me ocuparé de dichos ejemplos en el próximo apartado, para hacer algunas consideraciones más generales en la última parte ${ }^{12}$.

Comenzaré con un caso sencillo, para mostrar cómo los pisanos se servian de las acciones romanas como marco de sus procedimientos legales. Se trata de un pleito sustanciado ante el tribunal de los iudices publici, en Diciembre de 1159: la primera audiencia, de que se tiene noticia, de un tribunal comunal ante el que se utilizaron tales acciones. En el pleito, Ildebrando, sindicus (procurador legal) del cabildo catedralicio, interpuso demanda contra un laico llamado Quattromani por un marjal situado al Este de la ciudad, en Orticaia. Ildebrando reclamó a Quattromani una parte de dicha tierra, citando una condictio procedente de la ley de rebus et libertatibus iniuste ablatis vel invasis (Constitutum legis, 50): una acción contra la desposesión ilegal, sobre la base de que Quattromani había sembrado y cercado la tierra que los canónigos habían sembrado previamente (la primera persona que roturaba y sembraba una parcela gozaba, prima facie, del derecho de posesión en Pisa: una provisión importante en esa zona pantanosa y boscosa del delta del Arno). Para la otra parte de la tierra, Ildebrando citó el interdictum uti possidetis, una de las acciones posesorias romanas mejor conocidas (como, por ejemplo, en Institutiones, 4.15.4), usada cuando el demandante disfrutaba aún de la posesión y quería prevenir futuras desposesiones: evidentemente, Quattromani no había sembrado aún esta parte de la parcela. Quattromani lo negó todo, tanto

11 La presencia de abogados no se documenta en los registros de los tribunales, aunque su existencia es reconocida sin problemas en Constilutum usus, 8: Yale, MS. 415 , fol. 24 verso similar a BonalNI, F., Statuti inediti della città di Pisa dal XI al XIV secolo, op. cit., II, págs. 845-846.

12 Los juicios comunales y arbitrajes públicos que se conservan, mayoritariamente hacen referencia a asuntos de propiedad especialmente de la tierra y de las rentas y derechos afectos a la misma. No entro a analizar los casos relacionados con la ley criminal. Por otra parte, los registros judiciales se conservan básicamente en tres archivos: ASP, Archivio Capitolare di Pisa (en adelante $A C P$ ) y Archivio Arcivescovile, cuya documentación del siglo XII se encuentra registrada en $R P$. La documentación procedente de ASP y ACP se encuentra en su mayor parte correctamente editada en diversas Tesi di Laurea (Memorias de Licenciatura) del Dipartimento di Medievistica de la Universidad de Pisa, a las que me remitiré cuando proceda, o en D'AMIA, A., Divitto e sentenze di Pisa, op. cit. 
el que hubiera invadido tierra ajena como el que los canónigos pudieran invocar el interdicto, pues ellos nunca habian poseído la tierra en primer lugar. El litigio se centraría, desde ese momento, en quién había desbrozado la tierra antes; las dos partes aportaron testigos que manifestaron diferentes posiciones acerca de ello. Una de las cuestiones centrales vendría dada por la determinación de si el seto de los canónigos al extremo del marjal, que Quattromani había destruído, se había levantado sobre tierra nueva (como alegaban los canónigos, implicando que habían sido ellos quienes habían desecado la tierra) o, como Quattromani afirmaba, sobre terreno antiguo. Los jueces, en un experimento forense inusual, mandaron excavar en la parcela un hoyo de unos tres metros de profundidad, encontrando sólo tierra nueva en el fondo (evidentemente, la tierra drenada tenía una composición distinta), de modo que los canónigos ganaron el pleito. En este caso, el argumento se había alejado claramente de las especificidades del Derecho Romano, aunque el modo en que elaboraron el argumento de la primera posesion en las actuaciones iniciales estructuró todo el debate ${ }^{13}$.

Mi segundo ejemplo constituye, quizás, la argumentación más compleja que encontramos en los procesos de la Pisa del siglo XII; muestra lo que los pisanos podían hacer, si querían, con las leyes. La iglesia de San Pietro in Vincoli había levantado un edificio sobre una calle (un balatorium; en italiano, cavalcavia), detrás de la iglesia, desviando la calle por un túnel; un grupo de vecinos quiso impedirlo y llevó el caso ante los publici arbitri, cuya competencia comprendía toda obstrucción en las vías públicas (Constitutum usus, 43), y que oyo en audencia el caso el día 3 de Julio de 1178. El asunto, pese a que carecía de acciones romanas, que no solían usarse en la curia arbitrorum, fue estructurado sobre la base de argumentos romanistas. Ha sido analizado por diversos estudiosos, especialmente Celli por su utilización del Derecho Romano, y Garzella y Redi por la considerable información que proporciona sobre construcciones urbanas, dato muy valioso pues la cavalcavia todavía se mantiene en Via Palestro. Para las edificaciones urbanas, los dos últimos resultan imprescindibles y no repetiré sus argumentos. En cuanto al Derecho, sin embargo, habría algo que decir, pues se trata de un caso que ilustra muy bien lo que nos hemos propuesto ${ }^{14}$.

El texto de que disponemos consiste enteramente en argumentaciones legales. Evidentemente, los hechos no eran controvertidos, pues el edificio y

13 ACP 527, 16 de Diciembre de 1160 [1159], editado por SGHERr], R, I documenti dell' ACP dall' agosto II55 al 18 febbraio II76, Tesi di Laurea, Universidad de Pisa, a. c. 1963-64, rel. BERTOLINI, O., núm. 30. Sobre desbrozo de áreas pantanosas, vid. GIARDINA, C., «Le guariganga», en Storia del diritto, I, Palermo, 1963, págs. 135-185; para la hidrografía pisana, MAZZANTl, R., (ed.), La pianura di Pisa e i rilievi contermini, Roma, 1994, especialmente págs. 401-429.

14 ASP, Olivetani, 3 de Julio de 1179 [1178], editado por BENEDETTI, L., Le pergamene dell' ASP dal $1 / 75$ al $1 / 79$, Tesi di Laurea, Universidad de Pisa, ann. acc. 1965-6, rej. VIolaNTE, C., núm. 44. Véase también CELLI, R., Studi sui sistemi normativi delle democrazie comunali, op. cit, págs. 5l-54; Garzella, G., Pisa com' era, Pisa, 1990, págs. 217-219 y foto de la fig. 42; y Redi, F., Pisa com' era, Pisa, 199 ], págs. 302-303 y foto de la fig. 93.

Hispania, LVII/3, nủtm. 197 (1997) 981-1007 
sus propietarios se encontraban perfectamente a la vista; lo que se discutía era si se había quebrantado o no la ley al construirlo. Lamberto, sindicus de San Pietro, manifestó al comienzo, entre otras cosas, que los vecinos carecían de un ius prohibendi para paralizar la edificación, y que la mayoría de vecinos de la zona había mostrado su conformidad con ella. Sus oponentes lo negaron, pues privar de luces y aire a la calle impedía su uso; y tampoco creían que una mayoría de vecinos lo hubiera aceptado, aunque esto era, en cualquier caso, irrelevante. Lamberto afirmó que estos hombres en particular estaban excluidos de plantear ninguna prohibición porque ellos mismos habían construido canalones en sus edificios, conduciendo el agua directamente a la calle en per juicio de sus usuarios: era justo, por tanto, que los clérigos disfrutaran de los mismos derechos de construcción de que gozaban los laicos. En cualquier caso, la iglesia no disponía de espacio construido suficiente, y lo necesitaba; y otras cinco cavalcavie habían sido recientemente autorizadas en otras partes de la ciudad. Los vecinos respondieron que sus canalizaciones no afecta* ban al caso, pues era costumbre en todas las ciudades; y que los precedentes también resultaban irrelevantes, a tenor de uno de los textos más citados por parte de los glosadores, non exemplis set legibus sit iudicandum (Codex Justinianus, 7.45.13); con menor fuerza, también citaron en apoyo de sus argumentos un caso en que se había prohibido la construcción de una torre, y leyes contra la construcción de puentes. Lamberto replicó con argumentos igualmente débiles: que el Derecho (ius) dice que la ciudad no debe echarse a perder con ruinas, por lo que los edificios no pueden ser demolidos (Digesta, 43.8.2.17); que la iglesia tenía derecho a construir porque poseía el edificio subyacente, como mostraban los signa possessionis, cavidades y cornisas; y que tampoco podían sus oponentes prohibir la construcción, dado que no habian seguido el ritual correcto, es decir, el lanzamiento formal de una piedra, como se recoge en la ley (ius) is.

Hasta ese momento, ambas partes se habían arrojado argumentos, más o menos al azar, con la esperanza de derrotar al contrario. Es entonces, sin embargo, que llegaron al centro del problema, los términos exactos de la Constitutum usus, 43. Los vecinos argumentaron que los términos de la ley, Nulli liceat in via publica facere vel immittere unde via publica deterior fiat, se ajustaban perfectamente al caso. Lamberto lo negó, citando otros pasajes de la norma para probar que únicamente afectaba al suelo, no a la superficie levantada sobre él. Además, la norma había sido extraída de las leges (esto es, del Corpus Juris), donde se dice: Ne via publica superius vel inferius inpediatur merito; es decir, que el Derecho Romano prohibía construir sobre una via ${ }^{16}$. $\mathrm{Si}$ los conditores constituti hubieran deseado prohibir las construcciones

15 El lanzamiento formal de una piedra forma parte del Derecho Romano de prohibición, especialmente en las disputas sobre edificios: Digesta, 8.5.6.1, 39.1.5.10, 43.24.1.6, 43.24.20.1.

If Constitutum usus, 43: Yale, MS. 415, fol. 56 verso, citado casi igual por BonaINI, F., Statuti inediti della città di Pisa dal XI1 al XIV secolo, op. cit., II, pág. 954, aunque en éste se encuentran algunas adiciones significativas: hacia 1233 , existe con seguridad una cláusula sobre la balatoria.

Mispania, LVII/3, nủm. 197 (1997) $981-1007$ 
sobre calles, afirmaba Lamberto, habrían incluido esta última prohibición en la Constitutum de usu, cosa que no habían hecho. Los vecinos lo negaron, diciendo que la intención (mens et propositum) de los legisladores era impedir cualquier construcción que deteriorara (deterior) el viario, y esto inclúa, desde luego, el cubrir las calles, cosa que, además, facilitaba a ladrones, adúlteros y otros malhechores un lugar donde ocultarse. Por otra parte, si se concedía la autorización a San Pietro, resultaría imposible a los árbitros públicos prohibir dicha conducta en el futuro. Lamberto no contestó a esto, pero, en un argumento final, afirmó que los demandantes no eran quienes deberían haber planteado el caso sino que sólo aquéllos más afectados (cuius magis interest, frase de la Constitutum usus) estaban legitimados para ello; por el contrario, los demandantes habitaban hacia el lado sur de la cavalcavia, y sus arcos meridionales y centrales se encontraban allí desde hacía cuarenta años, incluso con un segundo piso en el arco meridional construido durante dicho tiempo. Este lado de la cavalcavia se encontraba, por tanto, protegido por el límite legal de las demandas; sólo la parte norte era más nueva, contaba únicamente dieciocho años, y los vecinos de este lado estaban legitimados para actuar. Los demandantes respondieron que esos límites legales no se aplicaban a los árbitros públicos; concluyendo así el caso.

Como ya he señalado, la cavalcavia aún permanece en pie: la iglesia evidentemente gano. Los árbitros fallaron enteramente en su favor, ordenando únicamente que las ventanas sobre el arco norte debían clausurarse; así mismo, el lado meridional podía levantarse más, en la medida en que sus ventanas no se proyectaran sobre las casas de los demandantes (además, todos los edificios de madera y desagües bajo el arco, debían ser removidos). No me sorprende que la iglesia ganara; su argumento sobre el límite legal es convincente, y su comparación textual entre la Constitutum usus y el Derecho Romano, muy elegante. Pero ambas partes demostraron ser inusualmente expertas en la argumentacion. Este documento es el mejor ejemplo que poseemos de un colorido debate romanista ante un tribunal, que se mantiene centrado en el caso en disputa y no se desplaza demasiado lejos de los puntos en discusión. Mantiene el interés dramático en cada página: uno desea saber cómo va a responder en cada ocasión la otra parte. En general, los contendientes demostraron un considerable conocimiento no sólo de los extremos del Derecho Pisano y Romano, sino también de cómo argumentar a partir de ellos. Incluso si dispusieron de consejeros legales, lo que es muy probable, pudieron desarrollar los argumentos ellos mismos. Su capacidad para discutir las intenciones de los legisladores pisanos a partir del uso que éstos habían hecho de los textos, es especialmente asombrosa; pero también lo es el uso del

Lamberto se mostró aquí muy inteligente pero también algo tramposo: Constitutum usus, 43 sigue de hecho, y muy de cerca, una de las normas romanas básicas en esta materia, Digesta, 43.8.2.20, como el mismo Lamberto seguramente conocia pues ya había citado dicha rúbrica con anterioridad. Sin embargo, la propia cita de Lamberto no procede directamente del Corpus Iuris. Digesta, 8.2 y Codex Justinianus, 8.10 .11 y 12 podian, desde luego, ser usados para implicar que era ilegal construir sobre la vía pública; pero podía disculparse a los constitutores por no haberlo observado.

Hìspania, LV11/3, núm. 197 (1997) 981-1007 
precedente como una advertencia a los árbitros y de la coletilla para destruir la argumentación de la iglesia de que otros habian ya hecho lo mismo.

Celli, en su estudio del caso, insiste en el expreso reconocimiento del Derecho Pisano como único Derecho soberano, y en la utilidad del Romano sólo para interpretarlo. Esto es, desde luego, importante. Sin embargo, lo que más me interesa es que ese conocimiento, tanto del Derecho Pisano como del Romano, permitió el desenvolvimiento de algo completamente nuevo: una argumentación exclusivamente normativa. Cada elemento de las afirmaciones de ambas partes derivaba de algún presupuesto normativo: bien de dichos Derechos, de una moral pública abstracta (la protección dada a ladrones y otros malhechores), de la equidad (los demandantes acusando a la iglesia de levantar una construcción que ellos mismos reconocían haber erigido) o bien de un precedente. El ámbito de la construcción urbana facilitaba argumentaciones de este tipo en Pisa: un caso sobre un albañal, ofdo en el mismo tribunal en Enero de 1193, igualmente basado en las Digesta, desarrolló una argumentación entre las partes menos sofisticada pero igualmente informada ${ }^{17}$. Argumentaciones parecidas en otras ciudades tendían a limitarse al establecimiento de los hechos, implicando que si los hechos aparecían claros, las conclusiones serían obvias. En Pisa no eran en absoluto obvias y, como hemos visto en 1178, las sutilezas legales podían emplearse por ambas partes. Podría afirmarse que esta actitud hacia el Derecho era simplemente el resultado de la adopción consciente, en 1.160, de un sistema legal tan amplio que permitfa a la gente no sólo asumir los principios del nuevo Derecho sino compararlo con sus fuentes y precedentes, tanto lombardos como romanos o consuetudinarios, en una forma en otras partes reservada exclusivamente a los juristas.

Observemos otro caso. Nero de Papiano intentó probar su libertad, es decir, que no era un colonus o manens semi servil, contra sus señores, los canónigos de la catedral, en una audiencia del 29 de Diciembre de 1177 ante los iudices foretaneorum. Se sirvió de la polivalente acción officium iudicis y de la condictio basada en la ley ne liberi homines obprimantur (Constitutum legis, procedente de la Lombarda, 3.10). Los canónigos se opusieron, afirmando que se trataba de un colonus y que su confessio lo probaba; su sindicus, Angelo, actuó a su vez, reclamando que Nero retornara a su tierra, sirviéndose de condictiones procedentes de las normas cum satis, cum scimus, y omnes omnino (Codex Justinianus, 11.48.23, 22, 6). Así mismo, Angelo enumeró los deberes de Nero para con los canónigos, sobre la base de testigos que aportaría que, en gran medida, confirmaba la misma confessio de Nero: que transportaba madera, prestaba sernas de trabajo, daba hospedaje (aunque lo hubiera redimido en parte por dinero), cuidaba sus caballos, se sometía al juicio de los canónigos, y otras, habiendo prestado servicio a lo largo de cuarenta años. Una sola de estas obligaciones, afirmaba Angelo, sería suficiente para demostrar que Nero era un colonus, por lo que debería retornar a su tierra.

17 D'AMIA, A., Diritto e sentenze di Pisa, op. cit., núm. XXIX, citando Digesta, 39.3.26. 
Nero respondió señalando que los testigos de los canónigos demostraban que había nacido de madre libre, y que esto era suficiente para establecer su libertad, de acuerdo con la ley justinianea Si quis natus ex libera persona et altera ascripticia (una cita libre de la Novella, 54, que sigue al Codex Justinianus, 11.48.24; leyes que, desde luego, apoyaban su caso). Además, aun cuando los testigos afirmaron que él era un arrendatario del cabildo catedralicio, realmente no lo era de éste sino del arzobispo. A esto se opuso Angelo, exponiendo que incluso si otras personas disfrutaban de derechos en parte de la tierra, los canónigos eran los domini y ellos ostentaban tanto los derechos posesorios como los de propiedad, especialmente sobre la condición personal. Con ello concluyeron las argumentaciones de ambas partes pero, como señalan los jueces, justo cuando se preparaban para dictar sentencia, inopinadamente Nero se allanó, admitiendo que era colonus de los canónigos y anunciando su intención de retornar a la tierra. Los jueces, entonces, determinaron que debería hacerlo así, citando el ius sobre la confesión (Digesta, 42.2) ${ }^{18}$.

Esta no fue una disputa aparentemente problemática. Los argumentos de Nero eran muy débiles; la relación de obligaciones serviles, hecha por Angelo, mostraba a primera vista que se trataba de un colonus o manens de los canónigos, lo que además Nero acabaría admitiendo, al parecer por su propia voluntad. Casos de este tipo, oídos en otros lugares de Italia, no citaban el Derecho Romano, aunque mostraban diversas similitudes: en cada caso, el argumento del señor se basaba en una lista de deberes, entendida por los observadores como signos de la condición personal. Pero el caso de Nero fue construido sobre normas concretas, tomadas directamente y en detalle del Corpus Iuris (las constituta pisanas no se extendían demasiado sobre el particular), citado por ambas partes y también por los jueces ${ }^{19}$. De hecho, incluso la palabra colonus era un préstamo del Derecho Romano, que se hizo más común en toda Italia en el siglo $\mathrm{xI}$, tendiendo a reemplazar a términos locales como manens o villanus en muchas áreas; como ha afirmado Francesco Panero, la amplia legislación tardo-romana sobre el colonato contribuyó al empeoramiento de su posición legal en la Italia septentrional y central en el período ${ }^{20}$. Esta no fue probablemente la cuestión en esta disputa; en cualquier caso, los canónigos no sólo elaboraron su caso con una lista de signos

18 BONAINI, F., «Diplomi pisani inediti e regesto delle carte pisane che si trovano a stampa», en Archivio storico italiano, VI. 2, suppl, I (1848-89), págs. 64-67 (se trata de documentación procedente de ACP). La cita de la Constilutun legis procede de Yale, MS, 415 , fols $\ 6$ verso, -17 recto. Para el Derecho Lombardo, vid. M. G. H., Leges, IV, Hannover, 1865, págs. 551 y 636; véase también STORTI STORCHI, C., «Il costitutun legis pisano nella redazione del manoscritto di Yale. Prime notem, op. cit.

${ }_{19}$ Cfr. la cita de la Constitutum legis en nota 19; Constitutum usus, 4I: Yale, MS. 415, fol. 56: Cfr, entre otros, un caso de dote en ASL, S. Lorenzo alla Rivolta, 18 de Marzo de 1165 , editado por Grust, A., Le pergamene dell' ASP dal 1157 al 1165, op. cit., núm. 69; en él se cita Constitutum legis, 33 y Digesta, 36.1.79.

20 PANERO, $\mathrm{F}$, Terre in concessione e mobilità contadina, Bolonia, 1984, págs. 242-6.

Hispania, LVII/3, núm. 197 (1997) 981-1007 
de estatus, sino que también desarrollaron sus consecuencias legales mediante la cita de las normas romanas relevantes para el caso, normas que, aunque no recogidas en la legislación pisana, se afirmaba que tenían fuerza de ley. Nero, por su parte, intentó elaborar un relato alternativo, reclamando un señor distinto; pero la base real de su demanda era exclusivamente normativa: si su madre era libre, entonces Justiniano establecía sin ambigüedad que él debería ser libre también.

El caso de Nero no precisaba realmente del Derecho Romano; habría concluido de la misma forma en cualquier otro lugar y por las mismas razones. Pero precisamente por ello, es importante como ejemplo del alcance que las formas pisanas de argumentar podian tener en una disputa ordinaria. Es probable que la posibilidad de un razonamiento normativo significara que si una parte se servía de él, la otra debía hacerlo igualmente; las dos, en todo caso, consideraron necesario hacer explícitas sus conclusiones y apoyarlas con citas detalladas de autoridades. El ambiente creado, por ello, resultaba muy distinto a los casos de manentia del resto de Italia. Y esta posibilidad de razonamiento normativo dio lugar a la verdadera novedad del caso: la demanda de libertad de Nero basada en las previsiones del Derecho Justinianeo. Es suficientemente asombroso que un campesino semi-libre tuviera acceso al Derecho - 0 , para ser más realistas, a un experto legal y al dinero para pagarle-; y más asombroso resulta que a ese campesino se le ocurriera buscar lo que el Derecho Romano legislaba, o, para el caso, que dicha norma pudiera aplicarse a su caso ${ }^{21}$. No se aplicó, sin embargo; la insistencia de Angelo en los cuarenta años —esto es, el límite legal-de prestación de deberes serviles fue, acaso, suficiente para asegurarlo, especialmente ante un tribunal probablemente hostil. El Derecho Romano era importante, pero aquí claramente tuvo sus límites.

Mediante un ejemplo final, examinaremos un supuesto distinto: el modo en que el Derecho Romano pudo adaptarse a la sociedad pisana y a las más tradicionales espectativas de los pisanos acerca de la forma de operar el Derecho. El 28 de Septiembre de 1177 dos árbitros, elegidos de común acuerdo por las partes, juzgaron un contencioso entre el arzobispo Ubaldo y el abad del monasterio rural de San Salvatore a Sesto, en la vecina diócesis de Luca, sobre propiedad de la tierra y derechos señoriales en el territorio de Bientina, diócesis pisana, a unos $6 \mathrm{~km}$. de Sesto. El caso no se juzgó en un tribunal comunal pero el arbitraje se acordó explícitamente que se resolvería tam per legem romanam quam et per bonum usum que legi non adversetur: la disputa se estructuró integramente mediante acciones romanas. El origen de la disputa fue dos parcelas de monte situadas en el extremo oriental de la frontera de la diócesis pisana, en las colinas Cerbaie (entre Bientina y el castillo lucano de Montecal-

21 Es posible que Nero hubjera podido encontrar algún experto legal que simpatizara con su caso; un jurista romano en la cercana Luca, Rolando di Guamignano, escribiendo en la década de 1.190 , se mostraba ciertamente hosti! a la opresión que comportaba la manentia: CONTE, E., Servi medievali, Rome, 1996, págs. 106-16. 
voli), una de las cuales demandaba el arzobispo contra el abad en virtud del interdicto unde vi y de la correspondiente condictio ex lege si quis in tantam (Codex Justinianus, 8.4.7), los procedimientos básicos romanos en caso de desposesión ilegal, y, de la otra, defendía su posesión a través del interdicto uti possidetis; tierra, esta última, que el arzobispo llegaría a mostrar a los árbitros. El abad, por su parte, reclamaba la posesión de una amplia franja de dicha tierra, aunque con diferentes límites, que así mismo mostraráa a los árbitros; fuera de dichos límites, reconocía la posesión del arzobispo sobre el monte ${ }^{22}$.

Ambos litigantes aportaron testigos, aunque el documento sólo recoge una relación resumida de lo que manifestaron. Los testigos del arzobispo afirmaron que sus custodes guardaban los límites que éste había mostrado a los árbitros, vendían la leña, ejercían derechos forestales y los cobraban a quienes cortaban madera dentro de dicha área, todo ello desde cuarenta años antes de la guerra entre Bientina y Montecalvoli (datada en 1172, siguiendo los Annales Pisani de Maragone ${ }^{23}$ ); en los cinco años siguientes a esa guerra, el monte había sido aprovechado con menor intensidad, en parte por temor a la guerra y en parte por encontrarse devastado, aunque los custodes se mantuvieron y, por tanto, también el arzobispo su posesión. Los testigos del abad no aportaron unas declaraciones tan bien estructuradas: se limitaron a manifestar que los hombres del abad, en Montecalvoli, habran utilizado el monte para leña y pasto durante cuarenta años, por lo que la posesión era suya. Los partidarios del abad añadieron, además, que cualquiera podía ejercer la guarda de un territorio puesto que se podía disponer del ius custodiendi sobre la propiedad de otro; que si los guardas del arzobispo prendaron arbitrariamente a otros (predari), eso no probaba un derecho (ius) sino, más bien, violencia; que la venta de madera no constituía posesión, sino disminución; y, finalmente, que cualquiera podía ejercer derechos forestales sobre la tierra de terceros mediante la violencia.

De este modo, el abad afirmaba que los violentos ataques por parte de los custodes del arzobispo constituían eso, mera violencia, y no probaban la posesión, como señalaron sus testigos ${ }^{24}$. Por su parte, los partidarios del arzobispo construyeron una elaborada contra-argumentación para apoyar su propia posición. En primer lugar, el hecho de haber vendido parte del monte, y de que los compradores hubieran a su vez vendido también, y ejercitado derechos forestales como parte de la venta, probaba que sus custodes no actuaban sólo en base a un ius custodie sino en virtud de un derecho de posesión. En segundo lugar, y cito,

22 Cfr: $R P$, núm. 525 y el caso contemporáneo núm. 526 . El Derecho que invocaron los árbítros era Romano, no Pisano, quizás porque una de las partes era de Luca.

23 Maragone, Bernardo, Annales Pisani, editado por Lupo Gentile, M., Rerum Italicarum Scriptores, VI, 2, Bolonia, 1930-36, pág. 57 (a. 1173 de la data pisana, 1172 de la moderna).

${ }_{24}$ Nótese que el caso sólo envolvió la posesión (y las acciones posesorias), no derechos de propiedad (una distinción romanista habitual en Pisa). Probablemente ninguna de las partes disponía de una base documental clara para afirmar la posesión del monte. Creo que la silva fue en un principio tierra fiscal, usurpada por ambas partes.

Hispania, LVst/3, núm. 197 (1997) 981-1007 
«Tampoco es plausible que nadie tome prendas si no es en defensa de su posesión; y, a menos que él [el arzobispo] lo poseyera, los habitantes de Montecalvoli nunca habrían sufrido la guarda de los custodes del arzobispo en el lugar. De to que debe presumirse (presummitur) que las gentes de Montecalvoli no tenían un derecho de uso del monte y pasto en virtud de un ius possessionis sino que lo ejercían en perjuicio de la custodia y forestatio [del arzobispo]. Déjese decir a los testigos [del abad] que vengarán las prendas que se les hicieron, pero no que sus derechos forestales se les deberían restituir».

Ahora, los mismos hechos usados por el abad son utilizados para deducir la conclusión opuesta: la violencia, en este caso, era una prueba conclusiva de derecho, y el hecho de que las gentes de Montecalvoli la hubieran tolerado, era una prueba de su aceptación. La conclusión se expresaba, así, en un estilo dialéctico romanista, aunque su contenido era el propio de la prueba consuetudinaria, no el del Derecho Romano.

$¿$ Qué es una prueba consuetudinaria? Utilizo el término para referirme a la asunción, general en la Italia del periodo, de que la defensa y público uso de una parcela de tierra probaban, en sí mismos, el derecho sobre ella. Una prueba que podía venir dada por una acción repetida en el tiempo (por ejemplo, alguien que cultiva continuamente dicha tierra y a la vista de otros), $o$, también, mediante actos aislados de especial relevancia simbólica, como la defensa violenta de la tierra. Ello no resultaba enteramente contrario al Derecho Romano, que habria aceptado sin problemas el uso continuado como una prueba prima facie de posesión; y la violencia, también, podía usarse para prevenir la desposesión en el Derecho Romano ${ }^{25}$. Pero los italianos de este período llevaron el argumento más lejos: la violencia, si no era contestada, se convertía en una prueba de derecho, como argumentaba el arzobispo en la cita anterior. El Derecho Romano nunca habría asumido un tal argumento. Examinemos brevemente algunos casos similares, antes de retornar al que nos ocupa.

Entre 1130-50, el arzobispo de Pisa y el monasterio de Verruca disputaron sobre una parte de la Serra de Plaia, en Monte Pisano. En este caso, disponemos únicamente de una pieza testifical en favor del monasterio, que describía cómo la gente cortaba piedra, hacía carbón de leña, llevaba a pastar a los animales y cortaba helechos para el monasterio, en lo que sin duda era una de las partes más pobres del monte. Algunos testigos lo habían hecho ellos mismos, otros eran guardianes nombrados por el monasterio; todos atestiguaron el poder del abad para controlar la explotación del monte y para cobrar derechos sobre su uso. El abad controlaba parte de la Serra directamente y parte a través de Ranuccino di Montemagno, quien la poseía en feudo. Los testigos afirmaron, entre otras cosas, que cuando en cierta ocasión hombres del arzobispo entraron allí para cortar madera, al verles salieron huyendo, abandonando sus armas en el lugar; y en otra ocasión, cuando hombres del arzobispo

25 Vid. las rúbricas de las Digesta y del Codex Justinianos relativas a unde vit Digesta, 43.16 y Codex Justinianus, 8.4; y para la fuerza defensiva: Digesta, 43.16.1.27 y Codex Justinianus, 8.4.1. 
prendaban a uno que cortaba madera en el monte, el abad envió a su propia gente pro preda y recuperó la prenda; el abad, así mismo, prendó las herramientas de algunos hombres de Rezano (en la actualidad Nicosia, al Sur de Calci) que no habían pagado los derechos de pasto, leña y hierba, hasta que el representante del arzobispo en Calci les aconsejó que comenzaran a pagar los derechos de nuevo. El más claro de los testimonios fue el de Martino di Bernardo, que merece la pena citar, siquiera en parte:

«En cierta ocasión, acompaño a su tío Mincuccio a recoger helechos en el monte objeto de la disputa; el helechal se encontraba crecido y cortaron parte de él, momento en el que Ranuccino di Montemagno apareció con una podadera en la mano, y comenzó a decir: "No hacéis bien, pues yo sirvo esta tierra por el monasterio de Verruca". A lo que respondieron, "si te parece, pagaremos por ello". El no quiso vender, y les obligó a marchar, diciendo que "preferíría dejar los helechos aquí, pudriéndose, de modo que germinaran más abundantemente después, a que os los llevárais".

La retórica de la fuerza era, evidentemente, comprendida incluso por alguien que se encontraba en la posición de víctima: después de todo, se trataba de un testigo del abad ${ }^{26}$.

Por consiguiente, los usos tradicionales eran tanto más convincentes cuanto si los detentadores de los derechos amenazaban o atacaban físicamente a los infractores. Esto no se vio modificado por ningún cambio en el Derecho Pisano en 1160. Es el caso de un cazador de pajaros que actuaba en una isla en el Serchio, reclamada por los canónigos de la catedral en Diciembre de 1182-Enero de 1183, y que había abandonado su actividad en ella, según afirmaban testigos de aquéllos, "por miedo a los canónigos». Igualmente, el de un marjal, no lejos corriente arriba de la isla, que era reclamado por la ciudad contra los canónigos en Agosto de 1175; en este caso, los testigos de los últimos dijeron que nunca nadie había cortado allí leña o juncos, o sembrado grano, salvo en nombre de los canónigos o que lo hicieran furtivamente (furtim; que también podría traducirse mediante hurto) ${ }^{27}$. Las infracciones cometidas a la vista de todos se convertían en una declaración pública de derecho, un desafío para que la otra parte cediera o respondiera con mayor violencia o acudiera a los tribunales; si el desafío no era aceptado, se tendía a reconocer el mayor derecho del infractor. Por otro lado, las infracciones ocultas carecían de un valor de prueba, y, desde luego, por el hecho mismo de su

26 $R P$, núm. 421; el documento carece de data pero uno de los testigos hace referencia a la guerra de Mallorca de 1113-15, lo que permite fecharlo, siquiera sea de forma tan aproximada.

27 Vid., respectivamente, ACP, 644, 20 de Diciembre de 1183 [1182]; 646, 19 de Enero de 1183; and ASP, Bonaini, 23 de Agosto de 1176 [1175], editado por BENEDETTI, L., Le pergamene dell' ASP dal 1175 al 1179 , op. cit, núm. 7. Un caso paralelo se encuentra en ACP, 500-5, Agosto de 1156 [1.155], editado por SGHERru, R., I documenti dell' ACP dall agosto 1155 al 18 febbraio 1176 , op. cit., núms. l-6. Cfr. WICKHAM, Ch., «Ecclesiastical dispute and tay community», en Mélanges de l" Ecole Française de Rome. Moyen Age, CVIII (1996), págs. 7-93, especialmente págs. 75-79.

Hispania. LVl/3, nu่m. 197 (1997) 981-1007 
secretismo, facilitaban el reconocimiento del derecho de la otra parte (que el infractor ni siquiera había intentado desafiar públicamente). El presupuesto básico, el esquema dramático que subyace en estas secuencias, es que las pruebas consuetudinarias, amparadas en la violencia pública, demostraban el derecho y que, aun cuando la gente pudiera disentir respecto a lo que fuera correcto o incorrecto, todo el mundo aceptaba las reglas. El Derecho Romano, evidentemente, no cambió nada de esto; e incluso, en el asunto de Bientina, el arzobispo se serviría de argumentaciones romanistas para justificarlo.

Volvamos ahora a dicho caso para observar cómo se desenvolvió. Después de la defensa que hizo el arzobispo de sus custodes, la argumentación se dirigió hacia el tema de la posesión anterior, como era lógico dada la forma en que fue estructurado desde el principio. El abad aportó un documento en el que se mostraba cómo uno de sus predecesores había arrendado tierra en el monte, lo que a primera vista demostraba la posesión, y cómo los habitantes de Montecalvoli habían reconocido su control sobre los derechos del monte. Afirmó que, incluso si el arzobispo había poseído el lugar en alguna ocasión, había perdido dicha posesión en 1172 , «puesto que en tiempos de guerra no hay usus» y aún más porque el arzobispo Ubaldo no la reclamó cuando sucedió a su predecesor Villano en 1175. El arzobispo replicó que su posesión era anterior a la de las gentes de Montecalvoli, cuyo usus había impedido el ejercicio de su posesión pero no la había extinguido; el arrendamiento citado nada probaba contra esto. Tampoco la catedral, como persona jurídica, había perdido la posesión porque su pastor hubiera tardado en reclamar sus derechos; incluso así, la actuación de sus custodes la habría mantenido, y de igual forma operaría el census dado al arzobispo por los hombres de San Prospero por los derechos de uso, incluso en tiempo de guerra. El arzobispo poseía antes de la guerra, no el abad; y el abad tampoco pudo poseer durante la guerra, "como el anterior debate demostraba" (presumiblemente la misma argumentación del abad), de modo que sus reclamaciones sobre la posesión fracasaban. De esta forma concluyó la disputa. Los árbitros, entonces, resolvieron que el abad tendría la primera parcela de monte que el arzobispo reclamaba, y que éste obtendría el resto. Así, el arzobispo perdía la tierra que específicamente reclamaba al abad, pero se protegía de las más amplias demandas de éste. Esto fue probablemente un arreglo por el que Sesto acabó más beneficiado; pero, en realidad, parece haber dejado a ambas partes con el control de los territorios que explotaban en ese momento.

He traducido una parte de los argumentos de este contencioso, y sintetizado gran parte del resto, con cierto detalle. Y ello porque, aparte el fácil compromiso con que finalizó el caso, resultan especialmente claros y precisos. Parece haber habido un largo período, que llegaría hasta 1172, en que los hombres del arzobispo guardaron el monte y controlaron sus derechos, pero durante el cual los hombres de Montecalvoli también lo habían usufructuado, quizás pagando los derechos correspondientes contra su voluntad y, por ello, por la fuerza. La situación habría cambiado desde la guerra de 1172, porque la madera fue aprovechada mucho menos por los hombres del arzobispo. Así, el abad pudo reclamar, con cierta facilidad, que el usọ continuo de una parte 
del monte por los hombres de Montecalvoli otorgaba la posesión en favor de su señor, el monasterio de Sesto, aun cuando el arzobispo también reclamara la continua posesión en base a las guardas que ponía. No está claro si fue antes o después de 1172 cuando los custodes arzobispales defendieron su derecho tomando prendas; si sucedió después de 1172, eso explicaría el interés del abad en demostrar que la guerra causó al arzobispo la pérdida de la posesión, y también el énfasis que puso en denunciar la violencia ilegal de los custodes, más que argumentar que la ausencia de éstos probaba su posesión. Pudo ocurrir también que la tensión, incrementada después de la guerra, llevase al enfrentamiento directo de los rivales usuarios del monte. En conjunto, entiendo que en los últimos cinco años los hombres del arzobispo explotaron el monte con menor intensidad y, simultáneamente, ejercieron una mayor violencia para defenderlo; lo que permitió al arzobispo afirmar que el uso continuo por los hombres del abad constituía una nueva e ilegal desposesión, y al abad argumentar que la fuerza ilegal usada contra sus hombres se ejercía contra su propia posesión (especialmente si la posesión del arzobispo habia decaido debido a la guerra).

La conclusión de los argumentos resultó, en cualquier caso, problemática: ambas partes reclamaban la continua posesión hasta fecha reciente, siendo el uso de la fuerza tan solo un medio de defensa. Este era un problema de difícil argumentación en un caso estructurado sobre la base de la desposesión por la fuerza. La documentación muestra al abad, la parte físicamente más débil, también como la parte con una argumentación menos consistente (la afirmación de que alguien pudiera disponer de un ius custodiendi sobre la tierra de otro, me parece singularmente artificial) ${ }^{28}$; el que obtuviera tanto en la sentencia arbitral final es, probablemente, un simple tributo a la tenacidad que mostraron los hombres de Montecalvoli por perseverar en el uso continuado de parte del monte bajo cualquier circunstancia (aunque debió ayudar el hecho de encontrarse a tan sólo un $\mathrm{km}$. de su castello). No obstante, lo que realmente nos importa es la forma en que ambas partes montaron sus argumentaciones. En general, de un lado el arzobispo afirmaba que la violencia probaba su derecho, y del otro, el abad lo negaba. Pero ambas partes construyeron sus argumentos sobre una base explícitamente normativa, que debía mucho a la tradición jurídica romana: el abad se apuntó un tanto con el concepto de ius custodiendi, que negó el arzobispo; éste, sobre todo, reformuló el concepto de violencia como prueba consuetudinaria en términos jurídicos, mediante un argumento claramente normativo y nada usual. Ambos litigantes se mostraron profundamente disconformes en cuanto a lo que cada argumento probaba, como hacen normalmente las partes, pero en ningún momento dejaron de hablar el mismo lenguaje. El Derecho Romano, al menos en su versión pisana, se muestra aquí adaptándose a los presupuestos de la norma consuetudinaria, más que procurando cambiarla. Merece también

28 El significado de la rúbrica completa de Digesta, 41.2 es exactamente el contrario: véase la rúbrica 41.2 .3 .13 , más explícita aunque referida a bienes muebles.

Hispantia, LVI/3, túm. 197 (1997) 981-1007 
poner de relieve que existe una continuidad entre este contencioso y el de Nero, juzgado tres meses después: disputas que podrían haberse solventado fácilmente mediante pruebas testificales o la lectura de documentos (cosa que habría sucedido en otras partes de Italia), se desenvolvieron y meditaron aquí mediante la lógica jurídica, que había acabado por adaptarse a la forma en que las evidencias eran aportadas en otros lugares. Aunque las partes creyeron necesario este estilo argumentativo, el Derecho Romano no cambió las pruebas ni, en gran medida, el resultado de los juicios, y sólo rara vez pudo incorporarse a los tipos de estrategia que podríamos calificar de exitosos ante un tribunal. Pero, en cualquier caso, precisamente porque se ajustaba tan bien a las estrategias forenses usuales, transformó su base normativa en algo más explícito.

La densidad de la argumentación legal, vista en estos casos, puede encontrarse a lo largo de todo el período posterior a 1160 . Todos los litigios que la contienen resultan interesantes, aunque la discusión de otros no llevarfa mis propios argumentos mucho más lejos. Es suficiente con hacer notar que la argumentación romanista fue capaz de estructurar cualquier tipo de contienda e inclusa las disputas juzgadas ante cualquier clase de instancia. Acabamos de ver un arbitraje romanista; un modelo que podría observarse también en procedimientos de Derecho Canónico, como cuando en Julio de 1192 una simple disputa sobre si los parroquianos de una iglesia tenían derecho a elegir su capellán, concluyó con un debate entre los parroquianos y sus patronos tradicionales, los canónigos de la catedral, sobre si los Derechos Romano y Canónico (leges et canones) permitían o no la enajenación de las iglesias. Además, en toda clase de asuntos los aforismos legales romanos abundaban. Así, en un arbitraje en Mayo de 1178 acerca, entre otras cosas, de una posesión continuada, los demandados manifestaron que su posesión se había prolongado durante tanto tiempo que dominitum nactum esse, una glosa romana nueva para un argumento antiguo en disputas por la tierra en Italia. $\mathrm{Y}$ en un caso consular, en Noviembre de 1171, sobre devolución de ciertas velas de un barco después del final (presumiblemente acre) de un consortium comercial, la demandada, Flandina, una mujer propietaria del barco, afirmó que la reclamación del demandante era insuficientemente precisa pues había muchas velas en el barco, de modo que la demanda era in incerto, unde nulla sequitur condempnatio (una referencia al Digestum, 42.2.8) ${ }^{29}$. Los Derechos Pisano y Romano son ornnipresentes en estos textos, y una fraseología cuasijurídica pudo incluso haberse ido introduciendo en el vocabulario técnico del litigante corriente.

No obstante, como se ha dicho con anterioridad, se hace necesario mantener un equilibrio. A lo largo de este artículo trato de poner en evidencia tanto la extensión como el límite de la peculiaridad pisana. Todas las disputas ana-

29 Vid., respectivamente, ACP, 702, 22 de Julio de 193 [1192]; $R P$, ntim. 529 (a. 1178 ); D'AMIA, A., Diritto e sentenze di Pisa, op. cit., núm. XIl, de Noviembre de 1172 [1171], con un comentario en págs. 54-55.

Hispania, LVH1/3, núm. 197 (1997) 981-1007 
lizadas pertenecen al grupo de contenciosos pisanos en los que el debate se vio más influido por el conocimiento jurídico, generalmente el Derecho Romano. Incluso así, con la excepción del proceso de la cavalcavia de 1178, he argumentado que el Derecho Romano pudo ser fácilmente absorbido por asunciones locales más tradicionales sobre el funcionamiento de la prueba. Podría haber acentuado esto añadiendo casos en los que, aparte de las acciones iniciales, el debate podría haberse desarrollado tan fácilmente sin una argumentación jurídica, como normalmente sucede en el resto de Italia, constituyendo el establecimiento de los hechos el objeto principal de las partes, y apareciendo las normas relevantes al caso sólo implícitamente en el transfondo del mismo. Las pruebas consuetudinarias, de que se sirvieron en el proceso de Bientina, también encuentran numerosas analogías fuera de Pisa. Algo que no me parece tan sorprendente: es una ilusión imaginar que ni el más elaborado sistema legal, incluso si reforzado por un complejo y poderoso aparato coercitivo (lo que no sucedía en Pisa), pudiera transformar siempre, de la noche a la mañana, formas de disputar anteriores, particularmente en aquellos casos en que todo el mundo conoce los parámetros básicos en los que se mueve. No obstante, los casos analizados resultan importantes como guías de posibilidades. La argumentación de Nero, basada en las Novellae de Justiniano, la justificación que hizo el arzobispo de la fuerza probatoria de la violencia en el caso de Bientina, y el texto íntegro sobre el asunto de la cavalcavia, muestran cómo, a pesar de las viejas reglas en que todavía vivía aquella sociedad, un complejo entramado de conocimiento legal romanista, tanto de los textos (Corpus Iuris y Constituta) cuanto de los estilos argumentativos, fue entonces capaz de extenderse ampliamente por Pisa, y, además, de un modo creativo. En el apartado de conclusiones de este artículo me extenderé algo más en sus implicaciones.

Antes de estructurar dichas implicaciones, puede resultar útil resumir rápidamente, algunas de las similitudes y diferencias existentes entre los modelos argumentativos de Pisa y otras ciudades en el mismo período.

En primer lugar y a diferencia de lo que sucedía en Pisa, la argumentación forense en otras ciudades, incluso cuando era muy detallada, se caracterizaba por no ser explícita. Más que referirse a normas o desarrollar las implicaciones de los argumentos, los italianos tendían a presentar los hechos, en ocasiones en forma verdaderamente amplia, tanto si resultaban relevantes al caso como meramente ilustrativos o puramente retóricos, en orden a construir la imagen de un caso que tuviera una línea narrativa lógica y convincente. En Pisa, aunque los hechos en sí mismos resultaban evidentemente cruciales, las partes acostumbraban a presentar también lo más claramente posible sus implicaciones: bien explicando su pertinencia al caso concreto, bien mostrando cómo se ajustaban en el supuesto en cuestión al Derecho escrito, o bien combinando ambas líneas de desarrollo. Consiguientemente, la argumentación en Pisa resultaba muy a menudo explícita y articulada, incluso cuando no era enteramente romanista. Se puede argüir que fue precisamente 
este hacer explícitos los argumentos legales la consecuencia más importante de la "Recepción" del Derecho Romano en la ciudad; aunque, indudablemente, disponian también de un amplio bagaje de Derecho Romano que las partes podían utilizar con gran detalle.

Por otro lado, muchos de los presupuestos básicos de lo que he denominado pruebas consuetudinarias, fueron comunes a todas las ciudades: el efecto probatorio de las acciones repetidas en el tiempo, incluyendo los rituales, y las acciones directas individuales, incluyendo la fuerza, era aceptado de igual modo por los testigos, litigantes (con pocas excepciones) y jueces, en Pisa como en otras partes. La importancia dada a los testimonios en todas las ciudades aseguraba esta similitud, pues el pisano corriente no era, evidentemente, muy diferente de otro italiano en sus actitudes hacia los tipos de cosas que constitufan pruebas en sus vidas cotidianas. La importancia del conocimiento general, la publica fama («lo que la mayoría de los hombres dicen, como la define un testigo en un procedimiento pisano en Abril de 1192), como prueba en todas las ciudades resulta ciertamente clarificadora ${ }^{30}$. Podemos entender este conjunto de actitudes como potencialmente contradictorio respecto de aquéllas que presumía el Derecho Romano, y, en un sentido formal, a menudo lo fue. Pero también debemos admitir que esto no constituía un problema para los pisanos. Ellos aceptaban el Derecho Romano y las pruebas consuetudinarias y, a pesar de su interés por las argumentaciones explícitas, afrontaban sus inconsistencias según surgian, sin implicarse demasiado en ellas. En conclusión, los pisanos de finales del siglo xi no sólo tenían su propio y especial estilo legal, sino también su propia y especial comprensión de cómo ese Derecho podía ser ajustado a los valores de lo que, en otros sentidos, constituía una comunidad normal del siglo $x i$.

Teniendo en cuenta los últimos puntos, podriamos proponer que la práctica dialéctica pisano-romana no era más que un conjunto de reglas procesales especificas, perteneciente al mundo misterioso de los jueces, más que algo asumido por las gentes en su comprension de cómo funcionaban realmente los litigios. Después de todo, los elementos más romanistas en los procesos eran las acciones iniciales, que, a partir de 1180 aproximadamente, se hicieron cada vez más retóricas. Es también cierto que, otro contexto donde las citas romanas resultaban especialmente populares, fue el relativo a los detalles procedimentales, como cuando en el proceso de la cavalcavia, de 1178, el demandado afirmó que los demandantes no habían abierto el juicio con el ritual apropiado de arrojar la piedra (vid nota 15); o cuando en una demanda de Enero de 1193, el demandado argumentó que el caso era una popularis actio, que el demandante había actuado en su propio nombre, no pro publico, y que, por tanto, la demanda no debería admitirse. Tal interés por el procedimiento era común en Italia, especialmente en los juicios que se ofan ante los tribunales eclesiásticos, donde las irregularidades procesales, genuinas o no, eran usadas rutinaria-

\footnotetext{
30 ACP, 691, 16 de Abril de 1193 [1192].
} 
mente para evitar los juicios y motivar continuas apelaciones al Papa ${ }^{31}$. En Pisa, este interés por el procedimiento no era sólo más romanista sino también más visible que en otras ciudades. Pero una preocupación por el ritual procesal no constituye una guía directa para el conocimiento de las complejidades del Derecho; y, además, a menudo cae en la categoría de la retórica.

En cualquier caso, sería erróneo observar el Derecho Romano en Pisa como poco más que un juego retórico. En primer lugar, porque nunca era cuestionado, incluso cuando los demandados eran derrotados únicamente por argumentos romanistas. Habría sido fácil (incluso en el caso de resultar inútil) para los perdedores protestar contra una lógica judicial que les había resultado perjudicial, como se documenta que hicieron a menudo los campesinos en el período carolingio, a pesar de las menos flexibles prácticas documentales de la época; sin embargo, aquélos nunca protestaron contra la aplicación del Derecho Romano en ninguno de los casos que se han conservado ${ }^{32}$. En segundo lugar, y probablemente más importante, porque la lógica romanista se utilizaba incluso fuera de los tribunales, en los arbitrajes privados. También en los arbitrajes podemos encontrar con frecuencia acciones y argumentaciones romanistas; el caso de Bientina constituye un buen ejemplo, pero no es único. En ocasiones, las partes dicen explícitamente acudir al arbitraje para evitar tener que ir al "placitum", quizás por los costes, aunque eran bajos, o acaso para evitar la tensión que los tribunales podían conllevar, o quizás simplemente porque se buscaba el compromiso, que caracteriza a la mayoría de los arbitrajes pisanos ${ }^{33}$. Pero no parece que pretendieran igualmente evitar los elementos legales romanos, pues podían eliminarlos de los arbitrajes, y a menudo no lo hicieron. Como desde hace tiempo han señalado los teóricos del "realismo legal», el propósito fundamental de toda argumentación legal consiste simplemente en convencer a los jueces ${ }^{34}$. Los árbitros privados eran frecuentemente elegidos de entre los notables de la ciudad que habian sido magistrados comunales en años anteriores y tenían, por tanto, experiencia jurídica; tales árbitros pueden haber esperado, y por tanto incentivado, el uso de elementos legales romanos. Pero, una vez más, las partes parecen encontrarse preparadas para seleccionar en primer lugar árbitros con mentalidad romanista, conociendo el tipo de demandas que éstos favorece-

31 D'AMtA, A., Diritto e sentenze di Pisa, op. cit., núm. XXIX. Sobre las apelaciones al Papa, vid. WıскнAM, Ch., «Ecclesiastical dispute and lay community», op. cit., págs. 80-5. Ejemplos ilustrativos sobre la profusión retórica de acciones se encuentran en ACC, 28 de Abril de 1193 [1192]; ASP, S. Lorenzo alla Rivolta, 17 de Marzo de 1192, editado por CASALIN1, M. D., Le pergamene dell' ASP dal 1188 al 1192 , Tesi di Laurea, Universidad de Pisa, a.c. 1966-67, rel. VioLANTE, C., núm. 52.

32 Vid. MANARESI, C., I placiti del «Regnum Italiae», I, Rome, 1955, núms. 36 y 89, para los campesinos de época carolingia.

${ }_{33}$ Cerca de un tercio de todos los arbitrajes privados en Pisa, entre 1.160-1.200, utilizan acciones romanas. En relación con el placitum y el recurso a otras instancias, vid, entre otros, ACP, 751, 27 de Abril de 1200 [1199].

34 Vid. el ya clásico trabajo de FrANK, J., Law and the modern mind, New York, 1930, págs. 3247 y $100-117$.

Hispania, LV11/3, núm. 197 (1997) 981-1007 
rían. La utilización de elementos romanos en los arbitrajes viene a mostrar que las reglas básicas del Derecho Pisano-Romano fueron aceptadas por la gente corriente tanto en la ciudad como, en la medida en que es discernible, en el campo.

La otra cuestion que debemos tener en cuenta, en este contexto, es que las sentencias en Pisa fueron en gran medida respetadas. La mayor parte de los casos oídos en los tribunales comunales tuvieron claros vencedores y perdedores; los acuerdos eran relativamente raros y en su mayor parte, salvo un par de casos, en asuntos de herencia o de construcción urbana; en general, los tribunales a veces concedian pequeñas compensaciones a los perdedores ${ }^{35}$, por lo que los magistrados no ponían especial cuidado en obtener su acuerdo. Pero, en cualquier caso, los perdedores cedían. Incluso cuando se ausentaban del juicio $\mathrm{y}$, entonces, se dictaba una declaración de contumacia contra ellos, rara vez se resistían: de hecho, sólo conocemos dos ejemplos de demandantes que tuvieron que volver al tribunal para ver confirmados sus derechos ${ }^{36}$. Cuando acudían al juicio, desde luego no se mostraban siempre contentos con el veredicto, pero no desafiaban a los tribunales. La violencia era considerada como algo normal por los pisanos, pero no disponemos de ningún documento en que se recoja un solo caso de violencia ejercida contra las decisiones de los tribunales.

Esto no sígnifica que la gente, en ocasiones, no negociara con el sistema legal. El ejemplo más interesante es el de Ghisla, viuda de Guido da Fasciano, un notable de la ciudad, que, en Enero de 1191, protestó contra el veredicto de un tribunal de apelaciones (esto es, contra una segunda sentencia) que dictaminó que su marido la había desheredado legalmente de cierta tierra al Este y Sur de la ciudad en favor del Hospital de Stagno. Esta logró forzar a sus victoriosos oponentes a acceder a un arbitraje en Marzo del año siguiente, el cual le concedió una alta indemnización de 203 libras; de este modo, no sólo consiguió pasar por encima de dos sentencias sino que incluso logró que los jueces cambiaran de opinión: uno de los árbitros de 1192 había sido uno de los magistrados en uno de los juicios anteriores. Era posible, por tanto, que las disputas se prolongaran tras la sentencia judicial, llegando a una última fase de arbitraje (de negociación), en orden a generar un resultado que el perdedor estuviera dispuesto a admitir; las mujeres, al menos las que procedían de la élite urbana, podrían encontrarse también entre estos perdedores de carácter tenaz. Ghisla no fue la única; otra mujer, Matilda, viuda de Mancari, logró que una demanda oída en un tribunal, se transformara en arbitraje, aceptando que los árbitros se eligieran entre sus oponentes, los canónigos de la

35 Pueden encontrarse ejemplos de arreglos en D'AMlA, A., Diritto e sentenze di Pisa, op. cil., múms. IX, de Diciembre de 1170 [1169], en un asunto de dote; y XXIX, Enero de 1193, en un asunto sobre construcción. Sobre las pequeñas compensaciones, $R P$, núms. 492 (a. 1166 ), 644 (a. 1199); y D'AMIA, A., citado supra, núms. XV, Julio de 1175 [1174], y XXVI, Enero de 1191.

36 D'AMIA, A., Diritto e sentenze di Pisa, op. cit., núms. IV, Diciembre de 1163 [1162] (en esta ocasión el demandado respetó la sentencia); y VIII, Julio de 1169 [1168] (ejecutando la declaración de contumacia que se había dictado en $\mathrm{V}$, dos años y medio antes): 
catedral, y alcanzando un compromiso final en 1174. Pero estas negociaciones, posteriores a las sentencias de los tribunales, no constituyeron ni implicaron amenaza ni rechazo a las decisiones legales. Se adecuaban a dichas decisiones, cuya fuerza era reconocida: si Ghisla aceptó entre sus árbitros a un juez que le había sido previamente hostil, y si Matilda aceptó que su caso fuera oído por sus oponentes, ambas, evidentemente, reconocían la legitimidad de las audiencias públicas anteriores, aun cuando, simultáneamente, intentaran pasar por encima de ellas ${ }^{37}$.

Lo mismo cabe afirmar respecto del sistema de apelación, que Pisa había desarrollado hacia 1200 . La apelación había sido prevista explícitamente junto con su propio tribunal, en las Constituta aunque, de hecho, el primer caso que se conserva es precisamente el de Ghisla, en 1191. Aunque a partir de entonces, encontramos un reducido pero continuo flujo de apelaciones, la mayor parte de las cuales, aunque no todas, confirmaría la sentencia de primera instancia. El procedimiento era generalmente aceptado: en el caso de Ghisla, y de nuevo en otro de Junio de 1202, encontramos incluso a los dos litigantes apelando sentencias en las que ambas partes habian sido parcialmente favorecidas por los jueces ${ }^{38}$. Pero la apelación no significa, desde luego, la negación del sistema legal, pues quienes apelan reconocen implícitamente la existencia de una jerarquía judicial que se controla a sí misma. Y la absoluta regularidad del sistema de apelaciones pisano, cuando éste fue desarrollado, revela la fuerza de la justicia pública de la ciudad, no su debilidad.

La conclusión a que debemos llegar en este punto, refuerza las paradojas expuestas en anteriores secciones de este artículo. Los pisanos aceptaron los presupuestos de su nuevo y muy romanizado sistema legal, incluso cuando entraba en conflicto con otros de sus muchos principios acerca de cómo lo correcto e incorrecto funcionaban, o de cómo se establecía una prueba. Más aún, ese nuevo sistema no convirtio los procedimientos judiciales urbanos en algo basicamente distinto, en su efectividad, de los de otras ciudades, que resultaban muy parecidos en sus rasgos básicos a los de Pisa pero muy diferentes en el Derecho que utilizaban. Ahora bien, es cierto que a priori sería difícil prever tal integración de dos sistemas normativos y el éxito razonable de los tribunales que se sirvieron de aquéllos. Pero también lo es que la carga de la prueba recae en quien afirme apriorísticamente que un sistema legal, elaborado y relativamente nuevo, sería tan eficaz resolviendo las disputas

37 Ghisla: D'AMlA, A., Diritto e sentenze di Pisa, op. cit., núm. XXVI, Enero de 1191; y ASP, S. Lorenzo alla Rivolta, 17 de Marzo de 1192, editado por CASALINI, M. D., Le pergamene dell' ASP dal $/ 188$ al $1 / 92$, núm. 52. Matilda: ACP, 585, 8 de Marzo de 1174, editado por SGHERr, R., I documenti dell' $A C P$ dall agosto $1 / 55$ al 18 febbraio 1176 , op. cit., núm. 88; cfr. 582, 29 de Noviembre de 1174 [1173], asi mismo citado por Sgherri, núm. 85, y 590, 31 de Diciembre de 1175 [1174], también citado Sgherri, núm. 93.

38 Vid. Constitutum legis, 17 y Constitutum usus, 47 : Yale, MS. 415 , fols. 5 recto- 6 recto y $62 \mathrm{r}$ vuelto), en relación con las reglas; sobre los casos después de Ghisla, ACP, 688, 1 de Febrero de 1192; RP, núms 639 (a. 1199), 644 (a. 1199), y, también para la centuria siguiente, CATUREGLi, N. (ed.), Le carte arcivescovili pisane del secolo XIII, I, Roma, 1974, núms. 6 (a. 1201), 17 (a. 1202, citado en el texto), 24 (a. 1203), etc.

Hispania, LV1U/3, núm. 197 (1997) 981-1007 
como otro anclado de antiguo en los valores tradicionales de una sociedad. En particular, un sistema nuevo y complejo, dotado de mecanismos legales rudimentarios para ejecutar sus decisiones, podría esperarse que causara considerables dificultades. $Y$ sin embargo, los pisanos se encontraban evidentemente preparados para aceptar los nuevos elementos romanistas en su Derecho y para reconocer rápidamente la legitimidad del argumento romav nista, incluso cuando se usaba en contra de ellos con éxito. Esta fue una elección que hicieron los mismos pisanos, no sus élites ni los teóricos del Derecho; fueron los litigantes, no los jueces, el factor primordial que permitió al Derecho Romano naturalizarse. $Y$ ello en parte porque los litigantes podieron, en ocasiones, reconstruir el Derecho Romano para adaptarlo a asunciones más tradicionales; pero en sí mismo, este hecho muestra el valor que le otorgaban aunque sólo fuera por la importancia de la imaginería romana para la identidad urbana de Pisa. Debemos concluir que, al menos en Pisa, el Derecho Romano no impidió la resolución exitosa de las disputas.

En cualquier caso, ¿sirvió de algo? Hubo una forma en que sí, una antigua pero importante forma en el desarrollo del ritual. Pues, visto desde un solo ángulo, la entera panoplia del Derecho Romano en Pisa fue, en sí misma, una compleja secuencia de rituales, desde las acciones iniciales a los actos finales de posesión. En la mayoría de las ciudades existía una cierta formalidad en el procedimiento judicial, como también una oportunidad para utilizar recursos dramáticos en el transcurso de las complejas argumentaciones que constituían las piezas centrales de los debates. En Pisa, cada elemento de dicho procedimiento era más complejo: la documentación inicial (una demanda escrita, registros de las declaraciones testificales $y$, pronto, de las confessiones de las partes), la complicación de las acciones, la posibilidad de argumenta" ciones eruditas, y la formalidad de los actos que ponían final a la contienda ${ }^{39}$. El Derecho Romano estaba en la base de cada una de estas complejidades procesales, salvo, quizás, de la última. Pero su resultado sorprende: creo que el proceso pisano de las décadas posteriores a 1160 constituye para cualquier ciudadano contemporáneo de las comunas urbanas el más elaborado ritual procesal, fuera de la liturgia de las más importantes festividades de la Iglesia y las prácticas del entorno inmediato del emperador y de las más importantes familias aristocráticas. Y los pisanos, al adaptarse al mismo, aceptaron un complejo sistema de procedimientos cuya lógica dramática se dirigra a la resolución de las disputas dentro del marco de las instituciones judiciales. Esa lógica contenía, por su misma naturaleza, un espacio para una sofisticada argumentación legal cuando una o (preferiblemente) ambas partes aceptaban asumirla; pero su utilidad real deriva simplemente de su complejidad y desenvolvimiento interno, que mantenía a las partes en él hasta que se alcanzaba el final de la disputa ${ }^{40}$. Pienso que ésta debe ser la razón principal que explica

39 Vid. D'AMIA, A., Diritto e sentenze di Pisa, op. cit., págs. 107-178, para la secuencia completa.

40 Vid. Davies, W. y FouraCre, P., (eds.), The settlement of disputes in early medieval Europe, Cambridge, 1986, págs. 232-237. Para un análisis antropológico del drama, TURNER, V., Dramas, fields and metaphors, Ithaca, 1974, págs. 23-59.

Hispania, LVII/3, núm. 197 (1997) 981-1007 
que no constituyera un problema para los pisanos que las pruebas romana y consuetudinaria no se ajustaran exactamente; pues estas últimas podían ajustarse fácilmente a la estructura dramática romanista de resolución pública de disputas en Pisa, y esto era lo que, en última instancia, realmente importaba.

En conclusión, me parece que la verdadera analogía al complejo Derecho pisano no se encuentra en el aparato judicial de su antecesor, el Bajo Imperio Romano, con todas sus posibilidades para desarrollar una coerción física extrema, sino más bien en el sistema legal de la Islandia de los siglos XII y XIII. Islandia, hacia 1200, disponía del más elaborado y complejo código legal de la Europa septentrional, centrado en una bien definida jerarquía de tribunales, pero sin un aparato coercitivo. Los islandeses sabían que el recurso a los tribunales simplemente formaba parte de un modelo más amplio de estrategias para disputar, y que debía ser respaldado con la construcción del mismo tipo de redes de apoyo que se necesitaban para lograr una resolución favorable incluso fuera de los tribunales, a través de enemistades [feuds, vendettas] y sus análogos. No obstante, valoraban el sistema judicial y todos aprendían tanto Derecho (y tantos ardides procesales) como podían, pues si ganaban en los tribunales, su posición estratégica en cualquier disputa se mejoraba considerablemente ${ }^{41}$. El Derecho islandés se encuentra lejos del pisano en el papel social que cumple; en la isla septentrional, una gran complejidad procesal significaba que era mejor apartarse de los procedimientos legales formales tan pronto como una salida negociada se hacía posible. El Derecho pisano dejaba más espacio para argumentaciones legales, y generaba victorias indiscutidas más a menudo que el islandés. Pero ambos sistemas muestran un mismo rasgo en común: su gran complejidad significa que, una vez que las partes decidían acudir a juicio, reconocían que las disputas probablemente acabarian por resolverse y no necesariamente en su favor, y ello sin necesidad de que se ejerciera un control sustancial por parte del tribunal y sus oficiales.

El sistema judicial pisano no era, como he destacado, completamente desconocido para el resto de los italianos. Sus pruebas eran general si no universalmente típicas en el resto de comunas italianas, incluyendo su aceptación de pruebas consuetudinarias; sus estructuras institucionales se parecian bastante a las de otras ciudades; la cultura del pisano medio, tanto en la ciudad como en el campo, era simplemente una variante local de la normal en Italia. El ritual judicial, que acabamos de enunciar, fue simplemente una versión más compleja de lo que sucedía en otras partes. Tal vez, a través de la incorporación de ese ritual, se trataba de neutralizar las complejidades del Derecho pisano; es decir, que éste se encontraba tan elaborado que sólo un elaborado ritual judicial podía contrarrestarlo y hacerle funcionar. La romanización de este sistema no supuso, por consiguiente, su total transformación. Pero, como igualmente he señalado con anterioridad, tampoco desearía minimizarla. El Derecho Romano hizo más fácil a los pisanos reconocer y hacer explícitas las bases normativas de sus argumentos. Asuntos, como el caso de la cavalcavia

41 Vid. Mllıer, W. l., Bloodraking and Peacemaking, Chicago, 1990, págs. 221-308. 
de 1178, dieron lugar a una nueva forma de argumentación, con un eje genuinamente forense y un efecto verdaderamente práctico, caso desconocido hasta entonces incluso en el Estudio de Bolonia. Aunque esto no era común ni siquiera en Pisa, ciertamente era posible. He afirmado a lo largo de estas páginas que su éxito no ha de darse por supuesto, y que únicamente fue alcanzado merced a los fuertes vínculos existentes entre el sistema legal pisano y los usos de la sociedad local, y al ritual dramático de los procesos judiciales: es decir, es de la disciplina de la antropologia legal más que del Derecho, de la que debemos servirnos como guía para analizar cómo funcionaba el sistema pisano ${ }^{42}$. Pero sí funcionaba, podemos observar el orgullo autosuficiente que destila el prólogo a la Constitutum usus y concluir que, en este aspecto al menos, los pisanos poseían algo que podían sentir legítimamente como propio.

Traducido por José Antonio Jara Fuente Centro de Estudios Históricos (CSIC-Madrid)

42 Para un modelo centrado en la Florencia del siglo XV, vid. KueHN, T., Law, family and women, Chicago, 1991, págs. 19-100.

Hispania, LVIL/3, núm. 197 (1997) 981-1007 